\title{
THE DESIGN OF WORK FACILITIES BASED ON WORKERS POSTURE ANALYSIS IN TOFU PRODUCTION MSME
}

\author{
Sanny Andjar Sari ${ }^{*}$, Salammia L.A ${ }^{1}$, Ida Bagus Suardika ${ }^{1}$ \\ ${ }^{1}$ Industrial Engineering, Faculty of Industrial Engineering, National Institute of Technology Malang \\ *Corresponding Email: sannysari@lecturer.itn.ac.id
}

\begin{abstract}
Work facilities following the user's needs are critical because they support the production process for increased productivity. Currently, the tofu production process at Mr Samingin's MSMEs uses manual equipment to feel pain in their body parts when doing work every day. Making tofu begins with washing the soybeans thoroughly, then soaking the soybeans in water for 2 to 3 hours. Sometimes, it needs 7 hours, depending on the type of soybeans. In this soaking process, the soybeans will expand and then cleaned again by washing them several times. The next step is to grind the soybeans into powder with a grinding machine then boiled them. Then, filter the soybean porridge with a cloth to separate the pulp to be processed and the rest of the cooking water. This stage is very tiring as it is done manually by filtering in a shake. In addition, in the process of pressing tofu, there is a lack of attention to workers' work posture, which will impact work-related pain, especially if it is done monotonously and repeatedly. This study used the Rapid Upper Limb Assessment (RULA) analysis method as a guide in designing tofu screening work facilities. It is expected that improvements to work facilities can increase worker productivity at tofu production MSME.
\end{abstract}

Keywords: Work Facility Design, Work Posture Analysis, RULA

\section{Introduction}

Tofu is one of the products of small and medium enterprises made from soybean (Glycine $\mathrm{Sp}$ ) and can be found in several regions. Start from urban to rural areas; the tofu-making industry has begun to be developed. This is because the tofu production process is quite simple, plus the government also provides space for the community to open and develop small and medium scale tofu production businesses. The number of entrepreneurs or tofu companies that have developed has had a positive impact, namely being able to meet the increasing market demand from time to time, opening up jobs around the factory environment, and reducing the unemployment rate [1].

One of them is the Small and Medium Enterprises in the tofu factory owned by $\mathrm{Mr}$ Samingin, which is engaged in food production, especially making tofu. This business was founded in 2017. Even though Mr Samingin has only started his business for about two years, Mr Samingin can employ around 5-10 people. Mr Usaha produces about $20 \mathrm{~kg}$ of soybeans a day. With $20 \mathrm{~kg}$ of soybeans, it is divided into two tofu products, namely, $12 \mathrm{~kg}$ of soybeans which becomes eight tubs of white tofu, and $8 \mathrm{~kg}$ of soybeans, which becomes 320 fried tofu seeds.

The owner markets this product through his marketing which is done every day. Making tofu is not that long; it takes a range of $4-5$ hours. The process of making white tofu is faster than fried tofu. Mr Samingin sells the product according to the price of soybeans because it dramatically affects income. However, Mr Samingin did not increase the price of the product. Mr Samingin only minimizes production until the price of soybeans returns to normal.

The initial process of available soybeans is washed thoroughly, soaked in water for 2 to 3 hours. Sometimes people soak for up to 7 hours. In this soaking process, the soybeans will expand and then cleaned again by washing them many times. Next, grind the soybeans until smooth with a grinding machine. After that, the smooth soybeans go straight to the following process, namely boiling. At this stage, the soybeans are boiled until they boil. Then, filter the soybean porridge with a cloth to separate the pulp to be processed and the rest of the cooking water. This stage is very tiring because it separates manually by using the filter in a shake. The water that comes out of the filter falls 
directly into the container that has been prepared under it.

After that, add vinegar to the tofu juice in the container while stirring using medium heat. Then place the tofu on the mould with a long storage time in the mould for \pm 15 minutes using a press. $\mathrm{Mr}$ Samingin's press is effortless by using only a table and wooden planks weighed with stones as a weight for the media press. This pressing process should only take \pm 15 minutes, but it makes the process longer and inefficient because it is too simple. The final step is cutting the tofu to the desired size and can be moved directly into the tub. For making fried tofu, cut it to size. The tofu can be fried immediately.The problem in this research is how to design work facilities that can reduce the risk of fatigue in workers at Tofu MSMEs, especially when processing the filtering of boiled soybean porridge.

Perform work posture analysis, which will later be used to make designs or designs and link in a quality matrix of a machine wherein previous studies have not done much [2]. Working conditions like this can cause injury to the muscles of the waist, back, wrists and joints in the fingers, resulting in fatigue and injury or are called Musculoskeletal Disorders (MSDs) [3]. The work of lifting and lowering an item that is done directly and repeatedly without the help of any tools can be a big risk factor for workers, such as aches and pains in the active parts of the body. There are several methods used to overcome work posture problems, one of which is the RULA method. The RULA (Rapid Upper Limb Assessment) method is a method for assessing the posture, style and movement of a work activity related to the use of the upper limb [4]. This method uses posture diagrams and assessment tables to provide an evaluation of the risk factors that workers will experience.

\section{Theoritical Review}

\subsection{Rapid Upper Limb Assessment (RULA)}

According to Lueder in Susihono [5], RULA is a method developed in ergonomics to invest and assess the work position performed by the upper body. This method does not require special tools to provide measurements of the neck, back, and upper body in line with muscle function and the external load supported by the body.

In Susihono [5], RULA is intended and used in the ergonomics field with a wide coverage area. Ergonomic technology evaluates posture or stance, strength, and muscle activity that results in repetitive strain injuries.

Ergonomics is applied to evaluate the results of the approach in the form of a risk score between one to seven; the highest score indicates the level that causes a considerable or dangerous risk to be carried out at work [6]. This does not mean that the lowest score will guarantee that the work under study is free from ergonomic hazards. Therefore, the RULA method was developed to detect work postures (upper limbs) at risk and repair them as soon as possible. This method uses the body postures chart and the four assessment tables to evaluate the hazardous work postures in the job cycle. Through this method, the maximum value and various postures of the worker will be obtained. The value of the limit ranges from $1-7$.

Processing work posture data in Susihono [5] using the RULA (Rapid Upper Limb Assessment) method through 3 stages, namely: Stage 1: Development of a method for recording work postures.

To produce a quick method, the body is divided into two parts: group A and group B. Group A includes the upper and lower arms and the wrists. In contrast, group B includes the neck, back, and legs. 


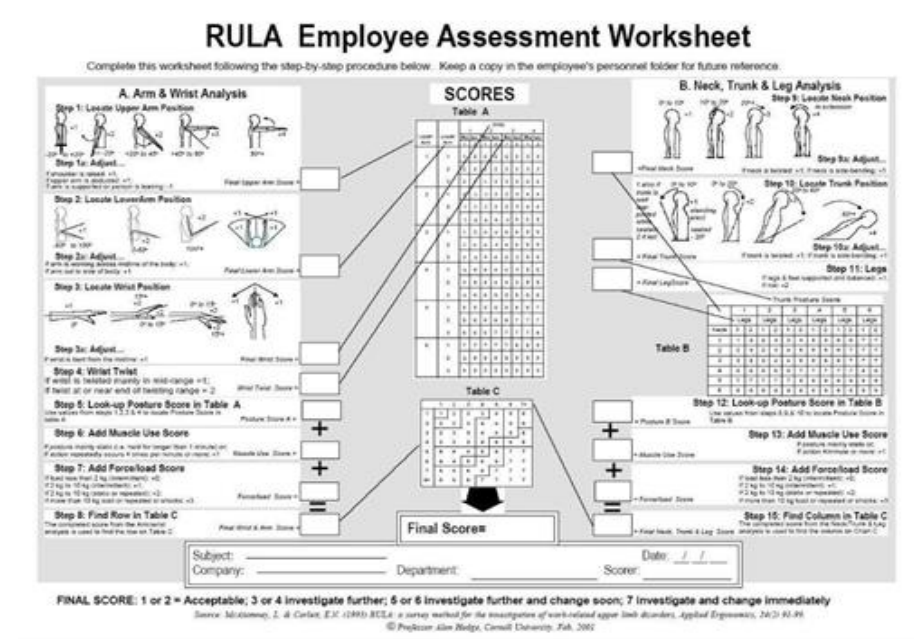

Figure 1 RULA Employee Assessment Worksheet [4]

\subsection{Anthropometry}

Anthropometry is a science that deals with the dimensions of the human body. These dimensions are divided into statistical groups and percentile measures. If a hundred people stand in a row from smallest to most extensive in order, it can be classified from 1 percentile to top 100 percentile. This human dimensional data is instrumental in product design to find the product's compatibility with the human who uses it.
In essence, body measurements obtained are very important in measuring the functional dimensions because they are closely related to the real movements that the body needs to carry out any particular activity [5]. In this case, the measurement of the distance between two points on the human body is predetermined according to the needs in the product design, where the distance is the shortest connecting line on the surface of the skin or more. Anthropometry is a measuring instrument with a unit of length in centimeters specifically designed for use by the human body.

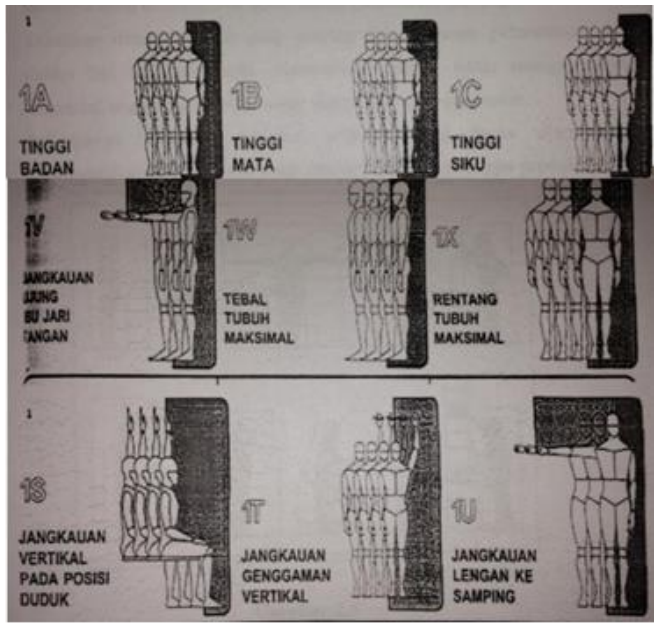

Figure 2 Dimensions of the Functional Body [4] 


\section{Research Methodology}

This study analyses and makes proposals for a more ergonomic work facility design based on the Rapid Upper Limb Assessment (RULA) analysis.

This research begins by evaluating the operator's work posture using the RULA method to determine priorities for improving facilities. Improvement of work facilities carried out is by applying anthropometry, which adjusts work facilities to the operator's body condition.

The research methodology is done by observing and interviewing ten workers in the UMKM tofu producer, Mr Samingin. The application procedure for the RULA method in carrying out work posture analysis uses:

a. Determine work cycles and observe workers during these variations in the work cycle.

b. Choose the posture that will be assessed.

c. Decided to assess both sides of the limb.

d. Calculating the grand score and activity level to assess the possible risks that occur.

e. Revise posture scores for different limbs that are used to determine where improvement is needed.

f. Redesign the workstation or make changes to improve posture when needed

g. If improvements have been made, it is necessary to reassess body posture using the RULA method to ensure that the improvement has gone as desired.

\section{Results and Discussion}

The worker in the tofu filtering section performs several elements of work, namely putting the ground tofu into the tofu filter device, starting the filter by shaking the tofu filter to separate the soybean slurry and water activity takes 45 minutes for $4 \mathrm{~kg}$ of ingredients soy porridge. Then transfer the filtered tofu dregs into the tofu pressing device. The assessment using the RULA method was carried out on the work posture of the filtering workers by classifying each body part according to the group of body parts in the RULA method. The following is the employee's work position when conducting tofu screening activities.

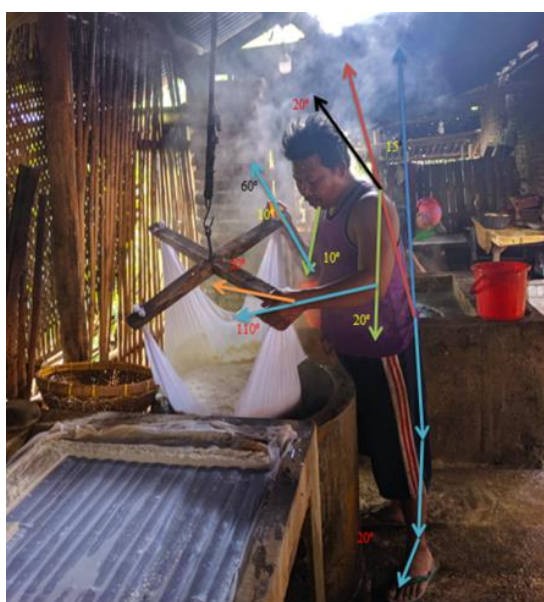

Figure 3 Measurement of the angle of the body is guided by the RULA method

From Figure 3, it can be seen that the right and left sides of the body when doing the screening process of soybean porridge with a slightly bent posture are in the same position, so the calculation of the score for work posture is enough to be done once.

a. Group A's posture

- The posture of the upper arm forms a 45o angle with the information that the $45 \mathrm{o}-90 \mathrm{o}$ angle is scored $=3$

- The posture of the forearm (lower arm) forms an angle of $100 \mathrm{o}$ with the information that the $60 \mathrm{o}-100 \mathrm{o}$ angle is scored $=1$

- The posture of the wrist forms an angle of $40 \mathrm{o}$ with the information that the angle> 15 o is scored $=3$

- Wrist twist The wrist rotation is in the middle of the round with a score of $=2$.

Assessment of group A's posture can be seen in

Table 1 below:

Table 1 Group A Posture Assessment

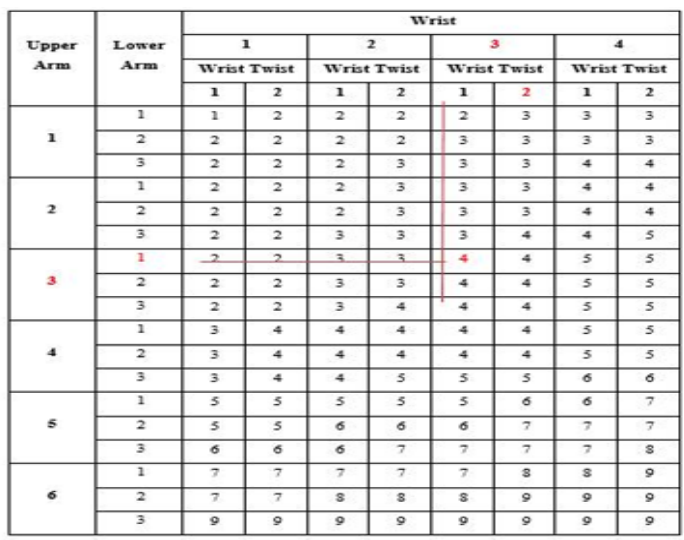


- The work posture score for group A based on table 1 is $=4$

- Activity score

The activity was not done repeatedly, more than four times/minute, with a score of $=0$

- Load score Occasional loading or exertion of more than two $\mathrm{kg}$ and holding $=1$ Total score for group $\mathrm{A}$ is $4+1+1=6$

b. Group B posture

- Posture of the neck (neck)

The neck forms an angle of 350 with the information that if the angle> 20o is given a score $=3$

- The posture of the trunk

The torso forms an angle of 450 with the information that the angle of $20 \mathrm{o}-60 \mathrm{o}$ is given a score of $=3$

- The posture of the legs is balanced with a score of $=1$

Assessment of group B posture can be seen in Table 2.

Table 2 Group B Posture Assessment

\begin{tabular}{|c|c|c|c|c|c|c|c|c|c|c|c|c|}
\hline \multirow{4}{*}{ Neck } & \multicolumn{12}{|c|}{ Trunk } \\
\hline & \multicolumn{2}{|c|}{1} & \multicolumn{2}{|c|}{2} & \multicolumn{2}{|c|}{3} & \multicolumn{2}{|c|}{4} & \multicolumn{2}{|c|}{5} & \multicolumn{2}{|c|}{6} \\
\hline & \multicolumn{2}{|c|}{ Legs } & \multicolumn{2}{|c|}{ Legs } & \multicolumn{2}{|c|}{ Legs } & \multicolumn{2}{|c|}{ Legs } & \multicolumn{2}{|c|}{ Legs } & \multicolumn{2}{|c|}{ Legs } \\
\hline & 1 & 2 & 1 & 2 & 1 & 2 & 1 & 2 & 1 & 2 & 1 & 2 \\
\hline 1 & 1 & 3 & 2 & 3 & 3 & 2 & 5 & 5 & 6 & 6 & 7 & 7 \\
\hline 2 & 2 & 3 & 2 & 3 & 4 & 4 & 5 & 5 & 6 & 7 & 7 & 7 \\
\hline 3 & -3 & 3 & 3 & 4 & 4 & 5 & 5 & 6 & 6 & 7 & 7 & 7 \\
\hline 4 & 5 & 5 & 5 & 6 & 6 & 5 & 7 & 7 & 7 & 7 & 8 & 8 \\
\hline 5 & 7 & 7 & 7 & 7 & 7 & 7 & 8 & 8 & 8 & 8 & 8 & 8 \\
\hline 6 & 8 & 8 & 8 & 8 & 8 & 8 & 8 & 9 & 9 & 9 & 9 & 9 \\
\hline
\end{tabular}
is $=4$

The posture score for group B based on Table 2

- Activity score

Activities are not performed by one or more static or stationary body parts with a score of $=0$
- Load score

Occasional loading or exertion of less than $2 \mathrm{~kg}$ and holding $=0$ Total score for group A is $4+0+0=4$

Table 3 Group C Body Posture Assessment

\begin{tabular}{|c|c|c|c|c|c|c|c|}
\hline \multicolumn{8}{|c|}{ Skor Grup B } \\
\hline Skor Grup A & $\mathbf{1}$ & $\mathbf{2}$ & $\mathbf{3}$ & $\mathbf{4}$ & $\mathbf{5}$ & $\mathbf{6}$ & $\mathbf{7 +}$ \\
\hline $\mathbf{1}$ & 1 & 2 & 3 & 3 & 4 & 5 & 5 \\
\hline $\mathbf{2}$ & 2 & 2 & 3 & 4 & 4 & 5 & 5 \\
\hline $\mathbf{3}$ & 3 & 3 & 3 & 4 & 4 & 5 & 6 \\
\hline 4 & 3 & 3 & 3 & 4 & 5 & 6 & 6 \\
\hline $\mathbf{5}$ & 4 & 4 & 4 & 5 & 6 & 7 & 7 \\
\hline 6 & 4 & 4 & 5 & 6 & 6 & 7 & 7 \\
\hline 7 & 5 & 5 & 6 & 6 & 7 & 7 & 7 \\
\hline 8 & 5 & 5 & 6 & 7 & 7 & 7 & 7 \\
\hline
\end{tabular}

The final results of measurements with the RULA method are in numbers 4 and 5, which means changes may be needed and changes are needed immediately by changing positions while working continuously and continuously.

Based on the RULA method to analyze the work posture of employees in the process of filtering soybean fertilizer as a primary ingredient of tofu, it is necessary to improve work posture with the redesign of work facilities, and this is to reduce injuries while working and so that it can create comfort and safety while working. For this reason, a work facility design proposal by applying worker anthropometry is needed concerning it as a guide in determining the tool's dimensions.

The anthropometry used for the design of the work facility can be seen in the Table 4 . 
Table 4 Anthropometric Percentile Calculation Results

\begin{tabular}{lcccc}
\hline \multirow{2}{*}{ No } & Kind of Data & \multicolumn{3}{c}{ Percentile $(\mathrm{cm})$} \\
\cline { 3 - 4 } & & $5 \%$ & $50 \%$ & $95 \%$ \\
\hline 1 & Standing Shoulder Height & \multicolumn{3}{c}{148,5} \\
\hline 2 & Forwards Reach & 72,16 & \\
\hline 3 & Side Reach & & 71,78 \\
\hline 4 & Standing navel height & 99,87 & \\
\hline 5 & Standing eye level & 151,5 & \\
\hline 6 & Standing elbow height & 93,4 & \\
\hline 7 & Standing Knee Height & & \\
\hline 8 & Index finger width & & \\
\hline
\end{tabular}

The work facility design as follows in Figure 4.

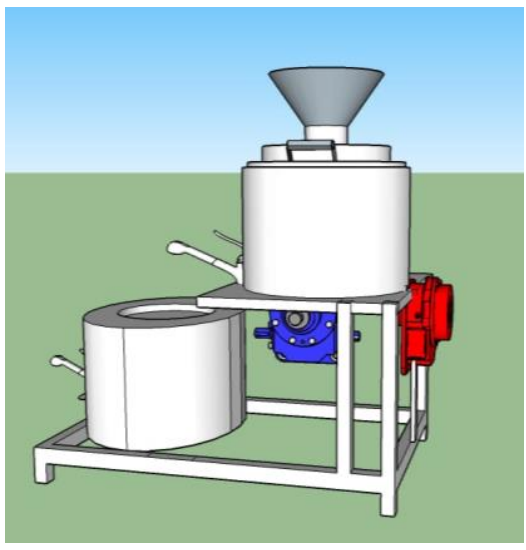

Figure 4 Measurement of the angle of the body is guided by the RULA method

Product Specifications are:

1. Capacity: $7 \mathrm{~kg}$

2. Frame Material: Iron Elbow

3. Tube Material: Stainless Steel

4. Electric Motor: $1 \frac{1}{2} \mathrm{HP}(1400 \mathrm{rpm})$

5. Dimensions: $60 \mathrm{~cm} \times 60 \mathrm{~cm} \times 110 \mathrm{~cm}$

6 . Overall Tool Weight: $\pm 30 \mathrm{Kg}$

\section{Conclusion}

1. Based on the analysis and discussion of work posture assessments at Tofu MSMEs, it can be concluded that the work posture of workers in soybean porridge filtering as the basic ingredient of tofu, the final score of the 3 positions is a score of 4,5 , and 5 . end 4 is included in the low-level category, which indicates that further examination is needed and that changes are also needed. For workers 2 and 3 , the final score obtained, namely 5 , is included in the medium category, which indicates that checks and changes need to be carried out immediately.

2. After analyzing the work of the workers in the pressing department, they know a need for improvement in work posture. In the form of an efficient and ergonomic tofu filtering tool design so that workers in Know SMEs, so as not to get complaints at work and even serious injuries in doing work.

3. The design of the soybean slurry filtering facility is carried out in accordance with the principles of ergonomics with the application of anthropometry.

\section{References}

[1] An-Nawawi, Imam. Matan Hadits Arba in Ariani, Farida, 2013. Analisis Postur Kerja dalam Sistem Manusia Mesin Untuk Mengurangi Fatigue Akibat Kerja pada Bagian Air Traffic Control (ATC) di PT. Angkasa Pura II Polonia Medan (Work Posture Analysis in Human Machine Systems to Reduce Work Fatigue at the Air Traffic 
Control (ATC) Section at PT. Angkasa Pura II Polonia Medan). Jurnal Dinamis, 2 (6). http://repository.usu.ac.id. 2010.

[2] Bangun, Elly Sabrina BR. 2009. Usulan Fasilitas Kerja Yang Ergonomis pada Stasiun Pengupasan di UD. Putri Juna (Proposed Ergonomic Work Facilities at the Stripping Station at UD. Princess Juna.). Tugas Akhir Sarjana. Fakultas Teknik Universitas Sumatera Utara. http://repository.usu.ac.id

[3] Safitri, Dian Mardi, Nabila, Zahra Arfi, Azmi, Nora, 2017. Design of Work Facilities for Reducing Musculoskeletal Disorders Risk in Paper Pallet Assembly Station. APCOMSIMEC.

[4] Jocelyn, D., 2018. Ergonomics and simulation-based approach in improving facility layout. Journal of Industrial Engineering International, 14, 783-791.

[5] Susihono, Wahyu Susihono, Rubiati, Endah, 2017, Perbaikan Metode Kerja Berdasarkan Rapid Upper Limb Assessment (RULA) Pada Perusahaan Konstruksi Dan Fabrikasi (Improvement of Work Methods Based on Rapid Upper Limb Assessment (RULA) in Construction and Fabrication Companies). Skripsi Jurusan Teknik Industri. Fakultas Teknik Universitas Sultan Ageng Tirtayasa.

[6] Vitasari, P., Gustopo, D., Indriani, S., Sinnadurai, S.K., 2020. A Survey to Identify Requirements in The Administrative Workplace. Journal of Sustainable Technology and Applied Science (JSTAS), 1(1), 1-6. https://doi.org/10.36040/jstas.v1i1.2524 